\title{
ENHIDE telehealth primary care support of adults with diabetes and chronic kidney disease: a pilot study - rationale and study design
}

\author{
PETER H WINOCOUR, ${ }^{1}$ KAREN MOORE-HAINES, ${ }^{2}$ ANDREW SOLOMON, ${ }^{3}$ ANNE CURRIE, ${ }^{4}$ \\ DAWN HARDY4
}

\begin{abstract}
Introduction: Diabetes is considered the main identified cause of end stage renal disease and this combination is becoming more prevalent as populations age and become more obese. Individuals with diabetes and chronic kidney disease (CKD) have additional multi-morbidity and may represent $\mathbf{2 5 - 4 0 \%}$ of those on diabetes registers in primary care, where the majority receive medical care. The East and North Herts Clinical Commissioning Group (CCG) commissioned the East and North Herts Institute of Diabetes and Endocrinology (ENHIDE) to pilot an innovative approach to the identification and care of this complex cohort in primary care. This paper reports the project design and objectives.

Aims: There were five core objectives of the pilot: (1) to examine the feasibility of extraction of comprehensive datasets from primary care diabetes registers; (2) to examine the feasibility of the individualised data utilisation for patient care; (3) to evaluate the practicality and acceptability of primary care of telehealth virtual case-based reviews; (4) to evaluate the extent of unmet clinical need; and (5) to create new sources of information to improve self-management. In addition, three key performance indicators were set for those with CKD: (1) change in any aspect of management in $20 \%$; (2) reduction of admissions and ambulance call outs for hypoglycaemia in $20 \%$; and (3) reductions in admissions with active foot disease by $20 \%$.

Study outline: All patients with estimated glomerular filtration rates (eGFR) $<60 \mathrm{~mL} / \mathrm{min}$ and/or urine albumin creati-
\end{abstract}

East and North Herts Institute of Diabetes and Endocrinology (ENHIDE), Howlands Clinic, QEIl Hospital, Welwyn Garden City, Herts AL7 4HQ, UK

1 Consultant Diabetologist and Clinical Director

2 Project Manager

${ }^{3}$ Consultant Diabetologist

${ }^{4}$ Diabetes Specialist Nurse

Address for correspondence: $\mathrm{Dr}$ Peter $\mathrm{H}$ Winocour Consultant Diabetologist and Clinical Director, East and North Herts Institute of Diabetes and Endocrinology (ENHIDE), Howlands Clinic, QEIl Hospital, Welwyn Garden City, Herts AL7 4HQ, UK

E-mail: peter.winocour@nhs.net

https://doi.org/10.15277/bjd.2019.215 nine ratio (ACR) $>10 \mathrm{mg} / \mathrm{mmol}$ were to be identified from practice diabetes registers enabling a holistic review of ' 15 pillars of care'. In addition to blood glucose management and review of renal function, this included recording of cardiovascular disease (CVD) and CVD risk factor status, risk of hypoglycaemia, assessment of anaemia, metabolic bone disease, foot and retinal health and hospitalisation.

Progress: The project was initiated in December 2016 and data are currently being updated for full analysis. 20 of the 55 general practices in the catchment area of the acute trust agreed to participate in the project, enabling case review of 2,874 cases. This initial phase of the pilot has established that the core principles of the project can be delivered in larger numbers, subject to developing new models of data capture and creation of clinically underpinned care algorithms.

Br J Diabetes 2019:19:53-62

Key words: diabetes, chronic kidney disease, Telehealth, care planning, clinical information systems, albuminuria, cardiovascular disease, hypertension, lipids, glycaemia, retinopathy, foot heath, metabolic bone health

\section{Introduction}

Diabetes mellitus (DM) remains the main identified cause of end stage renal disease in the UK. ${ }^{1}$ Chronic kidney disease (CKD) can be directly attributed to or associated with diabetes mellitus and is currently graded according to both estimated glomerular filtration (eGFR) and albumin excretion rates, with increased albuminuria still considered the hallmark of classical diabetic nephropathy. ${ }^{2}$ The incidence of both diabetes and CKD is projected to potentially double through the impact of ageing, obesity and improved case detection. The majority of cases with DM and CKD are likely to be older patients with type 2 diabetes. ${ }^{3-6}$

The current strategy on managing patients with DM with or at risk of CKD is to focus on glycaemic, lipid and blood pressure control, and national guidelines have been developed to support better management, ${ }^{7-11}$ recognising nuances of therapy selection in DM $C K D$, reflecting the impact of obesity and degree of renal disease.

Monitoring of renal function in DM has focused on measuring trends in both estimated GFR (eGFR) and estimates of proteinuria (usually urine albumin:creatinine ratios $(A C R))$. The current preva- 
lence of CKD based on both reduced eGFR and/or raised ACR is at least $40 \%$ of people with type 2 DM and up to $15 \%$ with type 1 DM. ${ }^{5}$ Current models promote delivery of most DM and CKD care in primary care settings. Criteria for specialist referral vary, but mainly reflect advancing proteinuria and/or progressive declining eGFR to the stage of end stage renal disease (stage 4 CKD, eGFR $<30 \mathrm{~mL} / \mathrm{min}$ ) or a fall of $5-10 \mathrm{~mL} / \mathrm{min} / 1.73 \mathrm{~m}^{2}$ over a year. 11,12

However, it is increasingly recognised that the co-existence of DM and CKD needs to be considered more holistically as a complex multi-morbidity disorder. ${ }^{5}$ Prevalent cardiovascular disease (CVD) and retinopathy are common, as are earlier manifestations of renal anaemia and metabolic bone disease. There is greater vulnerability to acute illness and hospitalisation with a range of issues including cardiovascular and foot emergencies, infections, hypoglycaemia and acute kidney injury. ${ }^{13-17}$

Failure to provide effective basic care of DM CKD has been reported in the UK and more widely. ${ }^{18-20}$ One primary care service has published successful review and improved care processes and quality core measures in DM with renal disease, but did not evaluate anaemia, CVD, bone, eye and foot health. ${ }^{21}$ Virtual clinical review of CKD and use of clinical support system decision-making tools have been reported in the management of CKD but have not focused on the wider care implications of the coexistent diabetes and related vascular disease. $22-24$

\section{Outline of the ENHIDE integrated telehealth renal project}

The National Health Service in England currently oversees the planning and delivery of healthcare through Clinical Commissioning Groups (CCGs) usually serving populations of 250,000-500,000. The East and North Herts CCG established a revised care pathway for diabetes care in 2010 whereby all referrals from primary care would be managed by a nurse-led single point of access. Those with specialist needs would either be managed in a community specialist nurse and consultant physician service or, if more complex, would be referred onto the hospital-based specialist services. Patients with advanced renal disease (eGFR $<30 \mathrm{~mL} / \mathrm{min}$ and/or nephrotic range proteinuria) would require referral directly to the nephrology services, but those with $A C R>30 \mathrm{mg} / \mathrm{mmol}$ and/or lesser degrees of CKD (eGFR 30-54 mL/min) were encouraged to be referred to the hospital diabetologist renal clinics. In addition, annual consultant diabetologist visits to all GP surgeries focused on virtual review of high-risk cases, especially those with levels of $\mathrm{HbA}_{1 \mathrm{c}}>75 \mathrm{mmol} / \mathrm{mol}$ and/or early onset complications or obesity and suboptimal control.

It was recognised that some patients with type $2 \mathrm{DM}$ and CKD presented late from primary care with poor control of glycaemia and CVD risk factors, advanced renal disease, established foot complications, previously unidentified and correctable metabolic bone health issues and complex anaemia, and had an increased risk for emergency ambulance call out with hypoglycaemia. This corroborated findings from the National Diabetes Audit, where there was poor attainment of glycaemic and blood pressure targets. ${ }^{18}$

Based on published literature, ${ }^{21,25}$ we anticipated the majority of those with DM and CKD would only be receiving primary care, but there was no information as to the extent of unmet clinical need.

In 2015 the East and North Herts CCG commissioned a 2-year pilot of a novel method of specialist review and support of patients with type $2 \mathrm{DM}$ and CKD diabetic nephropathy (DM CKD-DN) under primary care. The diabetes renal telehealth service set out to provide virtual holistic care of those with DM CKDDN identified on a practice-by-practice basis through the GP-held practice DM registers. The purpose of the pilot was five-fold:

1. To investigate the feasibility of extraction of comprehensive 'big data' from primary care information systems.

2. To enable clinical data utilisation for individualised virtual diabetes specialist review.

3. To evaluate the practicality and acceptability by primary care of a Skype telehealth virtual case-based discussion for the purposes of patient care and primary health care team upskilling.

4. To record the extent of unmet clinical need, frequency of suggested therapy changes and impact on discharge and referral patterns.

5. To develop strategies to improve self-management of foot health and acute illness with metabolic-renal decompensation.

This methodology paper describes the process for and challenges with establishing the project.

Initially all cases with ACR $>10 \mathrm{mg} / \mathrm{mmol}$ and/or eGFR $<60$ $\mathrm{mL} / \mathrm{min}$ were identified, but subsequently there was a more detailed focus on those aged $<75$ years and those aged $>75$ years with an eGFR $<45 \mathrm{~mL} / \mathrm{min}$ and/or $A C R>10 \mathrm{mg} / \mathrm{mmol}$. Patients under hospital specialist diabetes and/or renal care were identified and reviewed as well as those solely under primary care. Reports were initially created for both SystmOne and EMIS (Egton Medical Information Systems) primary care systems to enable identification of the numbers of patients from each practice with CKD. A database was created to enable extraction of the core measures and processes required for comprehensive DM CKD pillars of care (Figure 1). Standards of care were established based on the health status measures (Figure 2).

\section{Renal measures}

All available estimated GFR measures over a 2-year period from the most recent available result were reviewed in each case using the Integrated Clinical Environment (ICE) system. The biochemistry laboratory reported eGFR using the Modification of Diet in Renal Disease (MDRD) formula until July 2016 with a transitional period until March 2017 when reports were also provided from a different provider laboratory, from which time the Chronic Kidney Disease Epidemiology Collaboration (CKD-EPI) equation was used. For the purposes of the DM Renal Telehealth Project, we did not differentiate the two methodologies, given recognition that both estimates underestimate true GFR in diabetes but both perform equally in that regard. ${ }^{26}$ True deterioration in eGFR was recorded if there had been a persistent $10 \%$ reduction in eGFR from the value 2 years prior to the most updated result and/or a sustained reduction of $>10$ $\mathrm{mL} / \mathrm{min} / 1.73 \mathrm{~m}^{2}$ over the 2 years. eGFR results were classified as variable when they deteriorated by $10-20 \%$ but then improved to the same extent within the 2-year period without a progressive 
Figure 1. Care processes and data extraction form

\begin{tabular}{|l|l|}
\hline ReleHealth & $\begin{array}{l}\text { Addressograph } \\
\text { Name: } \\
\text { Date of Birth: } \\
\text { Gender: Male } \square \\
\text { NHS Number: } \\
\text { Hospiabetes and Endocrinology }\end{array}$ \\
\hline \\
\hline Practice Name:
\end{tabular}

Reasons for inclusion? eGFR $<60 \square \quad$ ACR $>10 \square \quad$ eGFR $<60$ \& ACR $>10 \square$ Progressive fall in eGFR but $>60 \square$

Patient Tests/Results:
1. eGFR
a) Checked in past 15 months? Yes $\square$ No $\square$
b) Result $<60$ Yes $\square$ No $\square$
c) Result.
d) Date:
e) Deteriorating
$\square$ Variable $\square$ Stable $\square$
2. $A C R$
a) Checked in past 15 months? Yes
No $\square$
b) Result $>10$ Yes $\square$ No $\square$
$\begin{array}{ll}\text { c) Result.............. } & \text { d) Date: }\end{array}$
e) Deteriorating
Variable $\square$ Stable $\square$

$\square$

3. Blood Pressure: a) Checked in past 15 months? Yes $\square$ No $\square$ b) Result........... c) Date:
d) $<140 / 80$ Yes $\square$ No $\square$ N/a $\square$
e) $<130 / 75$ Yes $\square$ No $\square$ N/a $\square$
f) Treatment .

$. \mathrm{N} / \mathrm{a} \square$

4. Lipids

a) Checked past 15 months? Yes $\square$ No $\square$ b) Date:
c) Total Cholesterol
d) HDL.
e) Non HDL.

f) Treatment.

g) Meets Non HDL Cholesterol Target Yes $\square$ No $\square$

5. HbA1c a) Checked in past 15 months? Yes $\square$ Noo b) Result........... c) Date:

d) Rising $\square \quad$ Variable $\square \quad$ Stable $\square \quad$ Improving $\square \quad$ No previous results to grade $\square$

e) Treatment

6. Hypo Enquiry a) Checked in past 15 months? Yes $\square$ No $\square$
b) Recent Hypos Yes $\square$ No $\square$
c) SAHE in last year
NK $\square$ 
Figure 1. Care processes and data extraction form (continued)

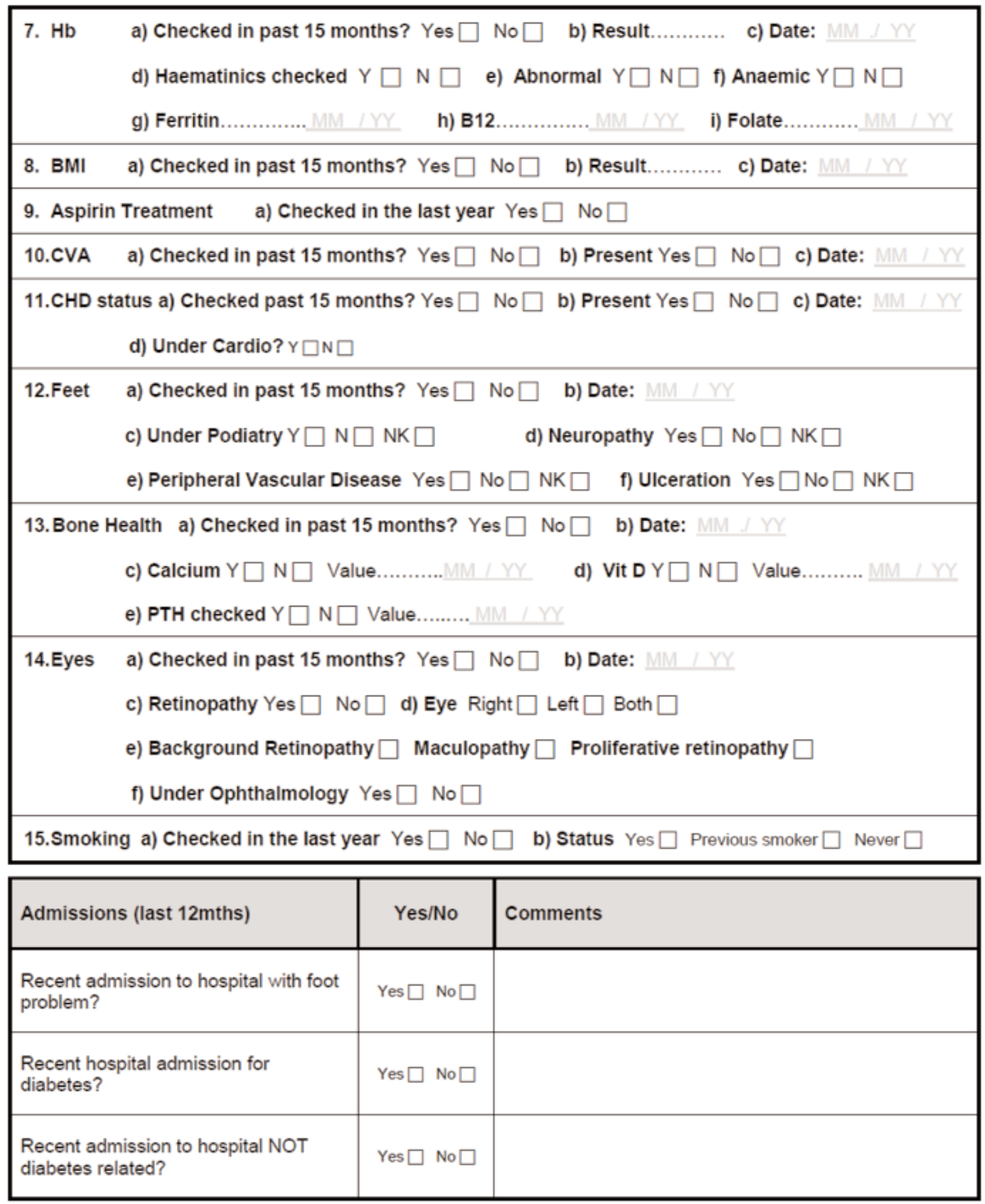


Figure 2. Holistic management of diabetes patients with nephropathy-chronic kidney disease

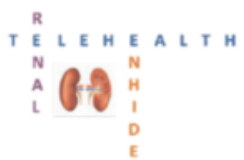
East and North Hertfordshire WHS

Holistic management of diabetes patients with nephropathv-Chronic Kidnev Disease (CKD)

Sick dav rule guidance especially important in all patients with CKD

\begin{tabular}{|c|c|}
\hline \multirow{3}{*}{ eGFR } & $\begin{array}{l}\text { eGFR - declines with age and is not validated in elderly }>75 \text {. eGFR more } \\
\text { reliable when EPI vs MDRD formula. May vary with hydration and protein } \\
\text { intake. Acute Kidney Injury trigger further decline with incomplete recovery } \\
\text { of eGFR. }\end{array}$ \\
\hline & $\begin{array}{l}\text { eGFR falling }>5 \mathrm{ml} / \mathrm{min} / \text { year considered sign of progression but given } \\
\text { variability suggest this is confirmed by repeated measurements to reveal } \\
\text { clear trend or fall of }>10 \mathrm{ml} . / \mathrm{min} / \mathrm{yr} \text {. seen over } 2 \text { years when referral to } \\
\text { renal dept. is suggested. }\end{array}$ \\
\hline & $\begin{array}{l}\text { Conservative care of frail elderly with falling eGFR below } 30 \text { (esp. below 15) } \\
\text { may require discussion with patient and potentially with renal dept. Age } \\
\text { itself would not preclude referral when CKD4 develops or deteriorates with } \\
\text { potentially reversible cause. All biomedical targets need to be reviewed. }\end{array}$ \\
\hline
\end{tabular}

\begin{tabular}{|l|l|}
\hline & $\begin{array}{l}\text { ACR - marked variability and persistent abnormal category important - i.e. } \\
\text { microalbuminuria ACR } 2.5(3.5)-10, \text { or } 10-30, \text { or }>30, \text { or marked evident } \\
\text { proteinuria (> 300) categories. If progressive rise across category consider } \\
\text { renal dept. referral especially in absence of retinopathy, in order to exclude } \\
\text { vasculitis-GN-myeloma -renal calculus and other causes of proteinuria. If } \\
\text { serum albumin falls nephrotic syndrome is suspected - renal dept. referral. } \\
\text { Renal vein thrombosis for sudden marked rise in proteinuria. Rare use of } \\
\text { dual RAAS (Renin-angiotensin-aldosterone system) blockade under specialist } \\
\text { care in marked proteinuria. }\end{array}$ \\
\cline { 2 - 3 } & $\begin{array}{l}\text { Monitor K (potassium) in all patients with DM - CKD-proteinuria as low renin } \\
\text { and/renovascular issues more common. Sub maximal dosing of RAAS } \\
\text { blockade with potential future K binders may enable higher doses. }\end{array}$ \\
\cline { 2 - 3 } & $\begin{array}{l}\text { Modest spironolactone dosage } 25 \text { mg may be helpful in proteinuria } \\
\text { reduction (as well as CCF) with } \mathrm{K} \text { monitoring. }\end{array}$ \\
\cline { 2 - 3 } & $\begin{array}{l}\text { Proteinuria reduction if achieved safely without deterioration in eGFR } \\
\text { and/or raised K is beneficial for DM nephropathy. Diltiazem has greater } \\
\text { proteinuric reduction effect than amlodipine. }\end{array}$ \\
\hline
\end{tabular}

\begin{tabular}{|l|l|}
\hline & $\begin{array}{l}\text { BP targets are 140/90 in DM CKD (150/90 frailer elderly) and 130/80 when } \\
\text { evident albuminuria. }\end{array}$ \\
\cline { 2 - 3 } & $\begin{array}{l}\text { Use of maximal dosage of diltiazem 240-300 LA, Ramipril 10, candesartan } \\
\text { 16-32 (esp. if retinopathy) -irbesartan 150-300- losartan 100 when } \\
\text { achievable indicated for albuminuria and retinal protection in established } \\
\text { microvascular disease. Diuretic use appropriate add on, where K elevation or } \\
\text { deterioration in eGFR attributed to RAAS blockade favour vasodilators - } \\
\text { hydralazine, doxazosin, and bisoprolol in preference. Avoid diltiazem with } \\
\text { beta blockers in high doses especially where documented bradycardia - } \\
\text { heart block } \\
\text { Monitor postural hypotension eps if elderly and or neuropathic }\end{array}$ \\
\hline
\end{tabular}

\begin{tabular}{|l|l|}
\hline \multirow{5}{*}{ Cholesterol } & $\begin{array}{l}\text { Use high intensity atorvastatin } 40-80 \mathrm{mg} \text { in majority of cases aiming at } \\
\text { non HDL cholesterol target of } 2.5 \mathrm{mmmol} / \mathrm{I} / \text { occ use of ezetimibe as add } \\
\text { on. Rosuvastatin up to } 20-30 \mathrm{mg} \text { if true atorvastatin intolerance. If } \\
\text { highest risk and intolerant of statins??? ezetimbe alone. Occ fenofibrate } \\
\text { for those with retinopathy-dyslipidaemia (may reduce eGFR modestly) } \\
\text { and in exceptional cases refer Dr Winocour-Viljoen Lipid service for } \\
\text { PCSK9 inhibitors (e.g. Evolocumab, Alirocumab) if established CVD and } \\
\text { statin intolerant and way off target }\end{array}$ \\
\hline
\end{tabular}


Figure 2. Holistic management of diabetes patients with nephropathy-chronic kidney disease (continued)

\begin{tabular}{|c|c|c|}
\hline HbA1c & \multicolumn{2}{|r|}{$\begin{array}{l}\mathrm{HbA} 1 \mathrm{c}-\text { consider carefully if anaemia. May be falsely lower if CKD4-5 and } \\
\text { occasionally falsely higher if untreated Fe deficiency. Complementary BGM } \\
\text { required. Targets vary - } 58 \text { for most and } 68 \text { in elderly. }\end{array}$} \\
\hline Hypos & \multicolumn{2}{|r|}{$\begin{array}{l}\text { If on SU-insulin and ? misleading HbA1c ep important to exclude evaluate for } \\
\text { hypoglycaemia especially where prior hypos - ambulance call outs or BG } \\
\text { levels over tight ( } 4-6 \text { pre-meal). Assess for hypo awareness. Hypos may be } \\
\text { atypical in elderly - if CKD declining err on side of caution re glycaemia } \\
\text { targets, Avoid SUs and insulin combo. If cognitive dysfunction extreme } \\
\text { caution if CKD. }\end{array}$} \\
\hline $\mathrm{Hb}$ & \multicolumn{2}{|r|}{$\begin{array}{l}\text { Annual check of } \mathrm{Hb} \text { in DM CKD - if } \mathrm{Hb} 110 \text { or less assess full haematinic inc } \\
\text { Fe balance studies. If potential Fe deficiency may still need referral e.g. } \\
\text { gastro, consider } \mathrm{B} 12 \text { deficiency PA-metformin and replace iron. If anaemia } \\
\text { review Hba1c in this light. Refer for haematology-renal if } \mathrm{Hb} 90 \mathrm{~g} / \mathrm{l} \text { ? EPO } \\
\text { (Erythropoietin) }\end{array}$} \\
\hline BMI & \multicolumn{2}{|r|}{$\begin{array}{l}\text { If BMI > } 30 \text { may adversely impact renal status ., Consider acco renal stats } \\
\text { role for weight reducing Rx such as gliflozins and GLP1 analogues according } \\
\text { to licensed indications by eGFR at present. Consider insulin sparing options } \\
\text { such as gliptins and minimise SU use. }\end{array}$} \\
\hline \multirow{2}{*}{ CVD } & \multicolumn{2}{|r|}{$\begin{array}{l}\text { If established CVD inc PVD and/or raised ACR consider antiplatelet therapy } \\
\text { with aspirin or alternatives }\end{array}$} \\
\hline & \multicolumn{2}{|r|}{$\begin{array}{l}\text { Highest CVD risk - record and review CVD - CVA - PVD status and take } \\
\text { account of lipid - BP - aspirin etc. choices }\end{array}$} \\
\hline Feet & \multicolumn{2}{|r|}{$\begin{array}{l}\text { Foot care - follow MDT foot care advice re high risk feet. DM CKD has } \\
\text { additional independent high risk beyond that attributable to neuropathy - } \\
\text { PVD which is more likely in CKD. Patient information card on foot protection } \\
\text { and seeking urgent care with Foot Attack-Ulcer- etc. to be encouraged }\end{array}$} \\
\hline $\begin{array}{l}\text { Bone } \\
\text { Health }\end{array}$ & \multicolumn{2}{|r|}{$\begin{array}{l}\text { Metabolic bone health when eGFR }<45 \text { annual PTH, vitamin D and } \\
\text { calcium/phosphare. If PTH }>2.5 \text { upper limit of normal (or very low vitamin D } \\
<30 \text { in CKD3b or worse) initiate activated Vit D ( } 1 \text { alpha } 250 \mathrm{ng} \text { and consider } \\
\text { dose increments if PTH does not fall). Review Ca status on the activated } \\
\text { vitamin D especially during acute illness }\end{array}$} \\
\hline \multicolumn{2}{|c|}{ Retinopathy } & $\begin{array}{l}\text { Retinopathy status - if active retinopathy and typical albuminuria CKD, } \\
\text { promote effective safe glycaemic control as stated prior and aim for } \\
\text { maximal RAAS blockade if renal status (eGFR-) enables this. If no } \\
\text { retinopathy and albuminuric CKD consider non DM causes as stated } \\
\text { earlier }\end{array}$ \\
\hline \multicolumn{2}{|c|}{ Smoking } & All patients who smoke should have access to smoking cessation \\
\hline \multicolumn{2}{|c|}{$\begin{array}{l}\text { Hospital } \\
\text { Admission }\end{array}$} & $\begin{array}{l}\text { This cohort have greater risk of hospital admissions (all causes including } \\
\text { infection) so especially vulnerable to chest infection requiring flu } \\
\text { vaccination. }\end{array}$ \\
\hline
\end{tabular}

decline. Episodes of transient deterioration in eGFR of $>10 \%$ were considered to represent potential acute kidney injury with a degree of recovery.

Urine ACRs were measured using a standard polyethylene glycol enhanced immunoturbidimetric assay for albumin and a standard enzymatic assay for urine creatinine, based on a requested early morning urine sample. All available ACR measures over a 2-year period from the most recent available result were reviewed in each case using the ICE laboratory system. Deterioration was documented if the values increased above $3.5 \mathrm{mg} / \mathrm{mmol}$ from below that value, and if they increased by more than $20 \%$ from the value 2 years prior to the most updated result.
Referral to the nephrology department was generally recommended when eGFR levels were $<30 \mathrm{~mL} / \mathrm{min} / 1.73 \mathrm{~m}^{2}$ and/or nephrotic range proteinuria was noted whilst not under specialist renal department care. In addition, atypical proteinuria without retinopathy and without concerns regarding glycaemic control would be considered for referral for renal review of non-diabetes causes of proteinuria.

$\mathrm{HbA}_{1 \mathrm{c}}$, blood pressure, lipids, use of related therapy and antiplatelet medication and body mass index

The most recent blood pressure was recorded from GP and/or hospital records and lipids and $\mathrm{HDL}$ and $\mathrm{HbA}_{1 \mathrm{c}}$ measures using 
the ICE laboratory system and evaluated if within 1 year prior to case review. The list of blood pressure, glucose and lipid-lowering medication was recorded from the downloaded GP records and Summary Care Records on the NHS spine where available.

A clinically significant change in $\mathrm{HbA}_{1 c}$ was documented if the values had changed by more than $10 \mathrm{mmol} / \mathrm{mol}$ from values 2 years prior to the most updated result. Those with $\mathrm{HbA}_{1 \mathrm{c}}$ recorded as $<50 \mathrm{mmol} / \mathrm{mol}$ on insulin and/or insulin secretagogue therapy with hypoglycaemic potential were considered to be at hypoglycaemic risk and coded accordingly.

Blood pressure targets were set at 140/90 $\mathrm{mmHg}$ without albuminuria and $130 / 80 \mathrm{mmHg}$ with albuminuria, with recognition that patients aged $>75$ might be conservatively managed with a blood pressure target of 150/90 $\mathrm{mmHg} .{ }^{8}$

Attainment of the non-HDL cholesterol target of $2.5 \mathrm{mmol} / \mathrm{L}$, in keeping with national guidelines, was determined. ${ }^{7}$

Use of aspirin was recorded from the medication record for each patient. Use of other antiplatelet agents and also warfarin and novel anticoagulants were recorded. Aspirin use or an alternative antiplatelet agent or anticoagulant was considered an appropriate standard for those with established CVD and/or raised albuminuria, in line with JBS3 guidelines. ${ }^{27}$

Body mass index was recorded from GP records and, where $>30$ $\mathrm{kg} / \mathrm{m}^{2}$, this was taken into account when recommending alternative diabetes therapies where glycaemic control was considered in need of improvement $\left(\mathrm{HbA}_{1 \mathrm{c}}>58,68,75 \mathrm{mmol} / \mathrm{mol}\right.$, according to age and presence of co-morbidities).

Referral to specialist diabetes care was recommended where glycaemic control remained poor $\left(\mathrm{HbA}_{1 \mathrm{c}}>75 \mathrm{mmol} / \mathrm{mol}\right.$ or there were documented issues with ambulance call outs for hypoglycaemia). Blood pressure $>160 / 100 \mathrm{mmHg}$ was also considered an indication for specialist referral.

\section{Hypoglycaemia enquiry}

This was recorded when coded from GP registers using the Read Codes for 'No significant hypoglycaemic attacks '(Y1028) or 'Hypoglycaemia identified' (Xa9Ao/Y1027), or recorded ambulance call out for hypoglycaemia (Y1029)

\section{CHD, CVA, smoking, feet status and podiatry access}

Documentation of these measures and activity were recorded from the downloaded GP records using appropriate 'Read Codes'.

Active foot disease or high-risk feet using standardised criteria ${ }^{28}$ were considered a basis for recommendation for foot care advice or podiatry referral if not already under such care. Smoking cessation priority was flagged up to the practices among smokers with DM CKD-DN.

\section{Retinopathy status}

The retinal status of patients was initially provided from the practice records if screening had been recorded in the last year. A more in-depth investigation was carried out from the East and North Herts Retinal Screening reporting system, an accredited service of the National Diabetes Retinal Screening programme.

Retinal status was recorded as available if within 1 year from the date of patient data review and recorded as to presence in one or both eyes and the level of retinopathy (background, pre-proliferative, proliferative or maculopathy).

\section{Metabolic bone health checks}

Documented results for serum calcium, vitamin $D$ and parathyroid hormone measures within 1 year prior to case review were taken from the biochemistry report system with the standard that they should be measured in those with eGFR $<45$, in keeping with national Renal Association guidance. ${ }^{29}$ Vitamin $D$ deficiency was set at total levels (vitamin D2 and D3) $<30 \mathrm{mmol} / \mathrm{L}$ using the National Osteoporosis Society criteria. ${ }^{30}$

Advice regarding initiation of activated vitamin $D$ from raised parathormone was set in line with guidance from the Renal Association based on progressive increases to values at least twice the upper limit of the reference range. ${ }^{29}$

\section{Anaemia}

Haemoglobin $(\mathrm{Hb})$ measurement within the past year from data review was set as a quality standard and values of $\leq 110 \mathrm{~g} / \mathrm{L}$ considered as anaemia, in line with the Renal Association NICE guidance. ${ }^{31}$ If $\mathrm{Hb}$ values were greater than this but with prior documentation of anaemia and on treatment, they were considered anaemic for the purpose of classification within the study.

Haematinics measured with or leading up to diagnosis of anaemia including reduced transferrin and iron, B12, folate and ferritin were recorded as evidence of haematinic checks and, where outwith reference ranges, considered as a record of abnormal haematinic levels.

\section{Hospital admissions}

Hospital admissions were recorded on the East and North Herts BIMS reporting system, based on hospital records for the 2 years prior to data review. Hospital admissions were recorded and separated into three categories: diabetes foot admission; other causes of diabetes admission; and non-diabetes admission.

\section{Governance}

This pilot was approved by CCG Caldicott Guardian. Ethical approval was not required given this was an extension of clinical care to implement national guidelines.

\section{Process of practice engagement and virtual review}

The CCG and project team promoted the new pilot service and set out to recruit 20 practices that were representative of the sociodemographic characteristics of the East and North Herts catchment area. The intention was to identify practices from each of the seven localities. Initially a virtual review of each case took place based on data extraction using a standardised data extraction form (Figure 1), with a recorded management plan fed back to the practice with additional investigations carried out at their next GP visit or annual review, depending on clinical urgency, with the support of the project diabetes specialist nurse if needed. The virtual review reviewed all 15 pillars of care to enable recommendations to be made regarding management change or referral. This included declining patterns 
of renal function, inadequate glycaemic, blood pressure and lipid control, consideration of hypoglycaemia risk, assessment for and investigation of anaemia, consideration of obesity in selection of diabetes therapy, assessment of cardiovascular status and record of antiplatelet therapy, assessment of bone health with parathormone measurement, assessment of retinopathy enabling consideration of non-diabetes basis for CKD, identification of foot risk requiring proactive podiatry advice or care, smoking as prompt to enable access to smoking cessation and identification of hospitalisation for diabetes-related and non-diabetes events.

Practices were offered a one-off fee of $f 200$ to enable purchase of a camera for computers and the subsequent Skype 2-hour telehealth meeting. Each participating practice had the option to engage in this, discussing a proportion of the cases with a training session built into the meeting. This session was open to all clinical staff at the practice.

Patients who were under the specialist hospital or community services with DM CKD who were reviewed and considered stable with all pillars of care adequately managed were planned to be discharged back to the practice for ongoing annual virtual review.

In contrast, all patients identified under primary care with poor glycaemic control, progressive renal dysfunction and/or important co-morbidities were to have care escalated for specialist hospital care in either the diabetes or the nephrology services.

All practices were supplied with individualised care plans for all patients in the high-risk criteria and expanded recommendations for 20 cases discussed at the Skype telehealth session.
In addition, all participating practices were supplied with a management summary for the pillars of care (Figure 2).

\section{Outcomes to be measured}

The primary outcomes were adherence to recommended targets and process measures in national guidelines and identification of unmet clinical need. There was an expectation of more proactive podiatric support and foot care advice and, in some older cases with CKD, more conservative glycaemic control with potential reduction in the rates of hypoglycaemia. A patient hand-held High-Risk Foot Card was developed for distribution to those with DM CKD with documented at-risk feet (Figure 3), and a patient credit card-sized Sick Day Guidance Card was produced for distribution by practices to all cases included in the renal DM review (Figure 4).

Three key performance indicators of the impact of the project were established by the CCG: (1) changes in any aspect of management in $20 \%$ of those with CKD; (2) reduction in admissions and ambulance call outs with hypoglycaemia in those with CKD by $20 \%$; and (3) reduction in admissions with active foot disease in those with CKD by $20 \%$.

Primary care feedback on Skype session

Overall feedback on these sessions was very positive. Responding GPs stated the importance of good communication for optimal management and the educational value and opportunity for discussions when there was uncertainty regarding referral to

Figure 3. High-Risk Foot Card for people with diabetes and chronic kidney disease

\begin{tabular}{|c|c|}
\hline $\begin{array}{l}\text { Your feet have been assessed as } \\
\text { being at High Risk } \\
\text { of developing diabetic foot } \\
\text { complications } \\
\text { This is because you have risk } \\
\text { factor(s) such as; numbness or foot } \\
\text { pain, poor circulation or foot } \\
\text { deformity in addition to moderate or } \\
\text { severe Chronic Kidney Disease. }\end{array}$ & $\begin{array}{l}\text { Please look after your feet as follows: } \\
\text { - Do not walk barefoot and check your feet daily } \\
\text { - Apply moisturising cream to your feet every night } \\
\text { - Please check the temperature of your bath water } \\
\text { with your hands } \\
\text { - Try to use wide-based footwear (with laces or } \\
\text { buckle) } \\
\text { - Check nothing is inside your shoes before wearing } \\
\text { Remember minimal trauma can cause skin } \\
\text { breakdown and ulceration in vulnerable feet }\end{array}$ \\
\hline $\begin{array}{l}\text { If you develop broken skin, an ulcer, } \\
\text { discolouration, swelling or pain, } \\
\text { please contact your GP straight away, } \\
\text { Explain that you have a } \\
\text { diabetic foot problem. } \\
\text { Outside normal hours, call the Out of } \\
\text { Hours GP or go to A\&E. }\end{array}$ & $\begin{array}{l}\text { Should you need advice or have } \\
\text { any concern(s) contact: } \\
\text { Hertfordshire Podiatry Service } \\
01727732004 \\
\text { Monday to Friday, } 8.30 \text { am }-4.30 \text { pm } \\
\text { (excluding bank holidays) }\end{array}$ \\
\hline
\end{tabular}


Figure 4. Sick Day Guidance Card

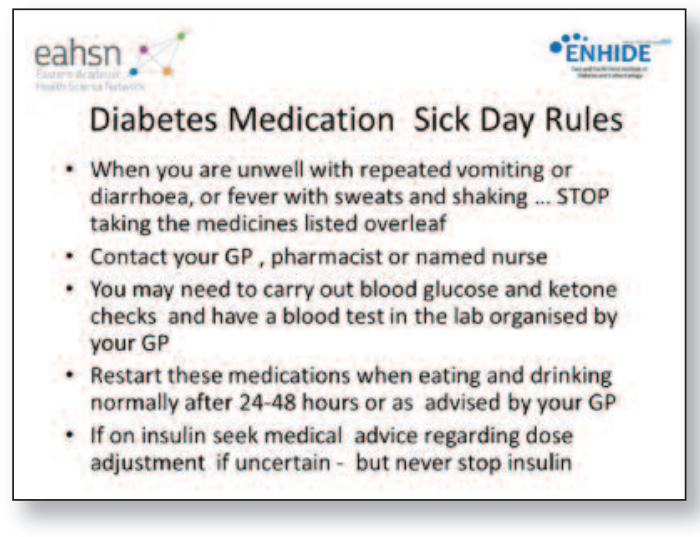

diabetes and/or renal departments. On a small number of occasions the audio and visual quality of the Skype call was poor, although this was intermittent.

\section{Progress and modification to protocol: challenges in project}

Of the 55 practices in East and North Herts, 20 agreed to enable data extraction and to take part in the 2-hour telehealth virtual review sessions.

The main challenges in establishment of the project were data extraction, data mergers and review of clinical information in other systems. Manual searches were often required if core information was not apparent after initial data downloads or was out of date. In addition, two different systems were used by primary care for recording patient information (EMIS Web and Systm One), with inconsistent capturing and recording of clinical information. Two of the practices were located at the boundary of the CCG catchment area and frequently used other acute trust clinical services and biochemistry which were closer to them and not readily accessible.

Corroboration of information required separate additional individual case review on digital retinal screening registers and the separate clinical information systems for those under specialist care. In addition, medication records on the main primary care systems only recorded the strength of medication rather than the prescribed dose. Subsequently, access to individual Summary Care Records enabled contemporary prescriptions including withdrawal due to adverse reactions to be recorded. Consequently, each individual case review required up to $30 \mathrm{~min}$ utes of individual consultant time.

After piloting this process in three practices, it became evident that the large caseload (approximately $25 \%$ of those on DM registers) meant there was inadequate time in the project to individually review every case. Subsequently, all patients under the age of 75 had individualised review and, in addition, those aged over 75 with eGFR $<45 \mathrm{~mL} / \mathrm{min}$ and/or ACR $>10 \mathrm{mg} / \mathrm{mmol}$ had individual case review.

The pilot service identified substantial unmet clinical need,
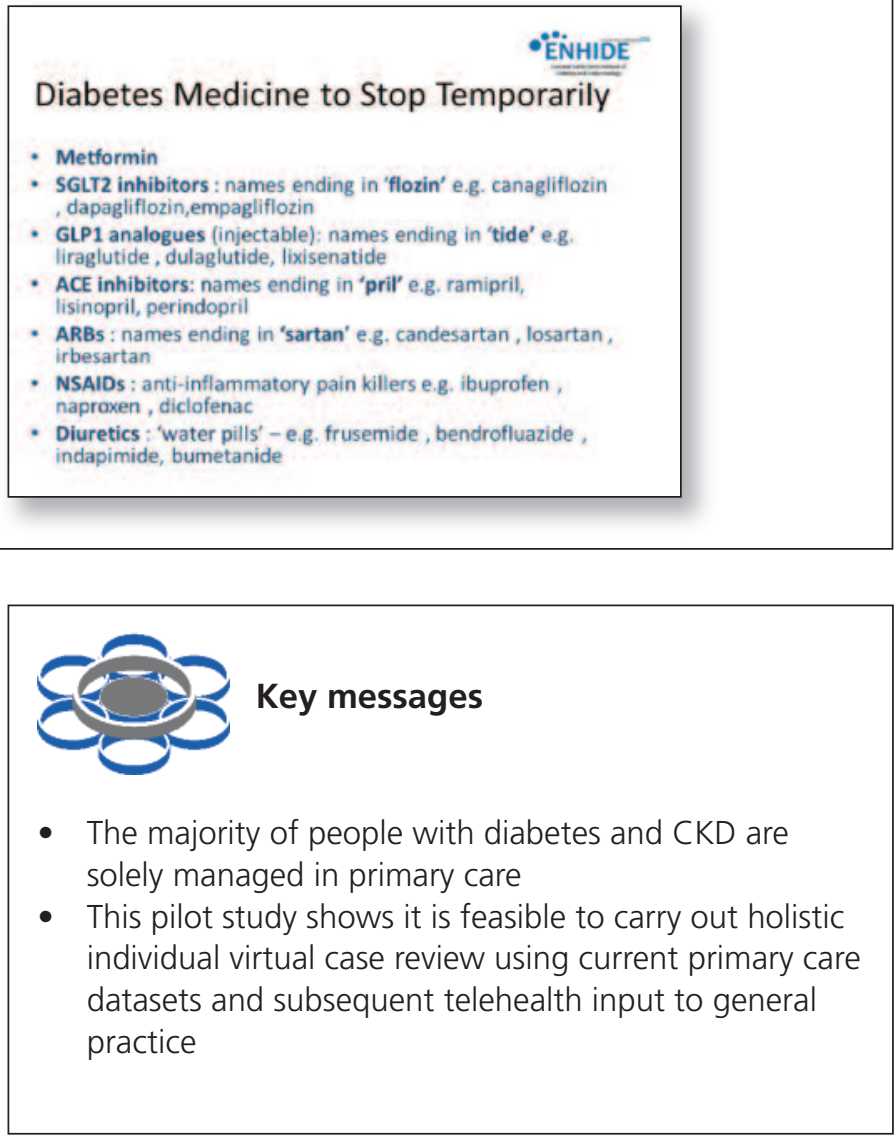

challenges in data extraction and a requirement for a cohesive approach to address the 15 pillars of care. In addition, high-risk vulnerable and/or disengaged patients were identified who could justify specialist clinic review but for a range of reasons were not able to access this. As of January 2019, the complete dataset is in the process of being refined and analysed.

\section{Summary and conclusions}

This pilot has successfully addressed the five core objectives established at the outset of the project, albeit with practical challenges in data extraction. Given the substantial numbers identified with complex and unmet clinical need, there is little doubt that a new care model such as this is required. Refinements in data capture and processing along with flexible telehealth contact between primary care and specialist teams can enable more effective integrated care of a large population with diabetes and complex multi-morbidity. Assessment of the key performance indicators will be best judged with ongoing evaluation and continuation of the project. Ongoing review of the medium-term outcomes is currently in process, but longer-term review will be necessary to better establish cost effectiveness and clinical benefits in respect of adverse foot and hypoglycaemia ambulance call outs. The project aims to evaluate both qualitative and quantitative beneficial changes in clinical management and outcomes 
and enable a new surveillance and service model that uses digital technology and an alternative to traditional outpatient reviews, given the large numbers with complex co-morbidity and the stated need of the NHS in England to redesign services. Once fully evaluated, we anticipate the future model will be streamlined to extract comprehensive data more readily and use a new clinical algorithm underpinned with specialist oversight to more readily identify those at greatest need of changes in clinical management.

\section{Conflict of interest: None}

Funding: This project was funded by the East and North Herts Clinical Commissioning Group with additional support from an unrestricted medical education grant from Sanofi Aventis towards diabetes specialist nurse salary costs.

\section{References}

1. Steenkamp R, Caskey F. UK Renal Registry 18th Annual Report: Chapter 6. Comorbidities and current smoking status amongst patients starting renal replacement therapy in England, Wales and Northern Ireland from 2013 to 2014. Nephron 2016;132(Suppl 1):145-54. https://doi.org/ $10.1159 / 000444820$

2. Kidney Disease Outcomes Quality Initiative (KDOQI). Clinical practice guideline for diabetes and CKD: 2012 update. Am J Kidney Dis 2012;60:850-86. https://doi.org/10.1053/j.ajkd.2012.07.005

3. Holman N, Forouhi NG, Goyder E, Wild SH. The Association of Public Health Observatories (APHO) Diabetes Prevalence Model: estimates of total diabetes prevalence for England, 2010-2030. Diabet Med 2011; 28:575-82. https://doi.org/10.1111/j.1464-5491.2010.03216.x

4. Ellam T, Twohig H, Khwaja A. Chronic kidney disease in elderly people: disease or disease label. BMJ 2016;352:h6559. https://doi.org/10.1136/ bmj.h6559

5. Winocour PH. Diabetes and chronic kidney disease: an increasingly common multi-morbid disease in need of a paradigm shift in care. Diabet Med 2018;35:300-5. https://doi.org/10.1111/dme.13564

6. Hill CJ, Cardwell CR, Maxwell AP, et al. Obesity and kidney disease in type 1 and type 2 diabetes: an analysis of the National Diabetes Audit. Q J Med 2013;106:933-42. https://doi.org/10.1093/qjmed/hct123

7. Mark, PB, Winocour P, Day C. Management of lipids in adults with diabetes mellitus and nephropathy and/or chronic kidney disease: summary of joint guidance from the Association of British Clinical Diabetologists (ABCD) and the Renal Association (RA). Br J Diabetes 2017;17:64-72. http://dx.doi.org/10.15277/bjd.2017.125

8. Dasgupta I, Banerjee D, Chowdhury TA, et al. Association of British Clinical Diabetologists (ABCD) and Renal Association clinical guidelines: hypertension management and renin-angiotensin-aldosterone system blockade in patients with diabetes, nephropathy and/or chronic kidney disease. Summary of recommendations. Br J Diabetes 2017;17:160-4. https://doi.org/10.15277/bjd.2017.152

9. Winocour PH, Bain SC, Chowdhury T, et al. Managing hyperglycaemia in patients with diabetes and diabetic nephropathy-chronic kidney disease. Summary of recommendations 2018. Br J Diabetes 2018;18:7889. https://doi.org/10.15277/bjd.2018.172

10. National Institute for Health and Care Excellence (NICE). Type 2 diabetes in adults: management. [NG 28]. December 2015. www.nice.org.uk/guidance/ng28

11. National Institute for Health and Care Excellence (NICE). Chronic kidney disease in adults: assessment and management. [CG182]. 2014. www.nice.org.uk/guidance/cg182

12. Bilo H, Coentrao L, Couchoud C, et al. Clinical practice guideline on management of patients with diabetes and chronic kidney disease stage 3 b or higher (eGFR $<45 \mathrm{~mL} / \mathrm{min}$ ). Nephrol Dial Transplant 2015;30(Suppl 2):ii1-ii142. https://doi.org/10.1093/ndt/gfv100

13. Tonelli M, Muntner P, Lloyd A, et al for the Alberta Kidney Disease Network. Risk of coronary events in people with chronic kidney disease compared with those with diabetes: a population-level cohort study. Lancet
2012;380:807-14. https://doi.org/10.1016/S0140-6736(12)60572-8

14. Otte J, van Netten JJ, Woittiez A-JJ. The association of chronic kidney disease and dialysis treatment with foot ulceration and major amputation. J Vasc Surg 2015;62:406-11. https://doi.org/10.1016/j.jvs.2015.02.051

15. McDonald HI, Thomas SL, Millett ERC, Nitsch D. CKD and the risk of acute community acquired infections among older people with diabetes mellitus: a retrospective cohort study using electronic health records. Am J Kidney Dis 2015;66:60-8. https://doi.org/10.1053/j.ajkd.2014.11.027

16. Davis TME, Brown SGA, Jacobs IG, Bulsara M, Bruce DG, Davis WA. Determinants of severe hypoglycaemia complicating type 2 diabetes: the Fremantle Diabetes study. J Clin Endocrinol Metab 2010;95:2240-7. https://doi.org/10.1210/jc.2009-2828

17. Lapi F, Azoulay L, Yin H, Nessim SJ, Suissa S. Concurrent use of diuretics, angiotensin converting enzyme inhibitors, and angiotensin receptor blockers with non steroidal anti-inflammatory drugs and risk of acute kidney injury: nested case-control study. BMJ 2013;346:e8528. https://doi.org/10.1136/bmj.e8525

18. Hill CJ, Cardwell CR, Patterson CC, et al. Chronic kidney disease and diabetes in the National Health Service: a cross-sectional survey of the UK National Diabetes Audit. Diabet Med 2014;31:448-54. https://doi.org/10.1111/dme.12312

19. Luk AO , Li X, Zhang Y, et al, for the JADE Study Group. Quality of care in patients with diabetic kidney disease in Asia: the Joint Asia Diabetes Evaluation (JADE) Registry. Diabetic Med 2016;33:1230-9. https://doi.org/10.1111/dme.12312

20. De Cosmo S, Viazzi F, Pacilli A, et al, and the AMD-Annals Study Group. Achievement of therapeutic targets in patients with diabetes and chronic kidney disease: insights from the Associazione Medici Diabetologi Annals initiative. Nephrol Dial Transplant 2015;30:1526-33. https://doi.org/ 10.1093/ndt/gfv101

21. Milne N. Improving the quality of diabetes care: an audit tool for chronic kidney disease. Diabetes and Primary Care 2014;16:78-83.

22. Harnett $P$, Jones $M$, Almond $M$, Ballasubramanian $G$, Kunnath $V$. A virtual clinic to improve long term outcomes in chronic kidney disease. Clin Med 2018;18:356-63. https://doi.org/10.7861/clinmedicine.18-5-356

23. Ennis J, Gillen D, Rubenstein A, et al. Clinical decision support improves physician guideline adherence for laboratory monitoring of chronic kidney disease: a matched cohort study. BMC Nephrol 2015;16:1-11. https://doi.org/10.1186/s12882-015-0159-5

24. Rayner HC, Hollingworth L, Higgins R, Dodds S. Systematic kidney disease management in a population with diabetes mellitus: turning the tide of kidney failure. BMJ Qual Saf 2011;20:903-10. https://doi.org/ 10.1136/bmjgs-2011-000061

25. Jones RK, Hampton D, O'Sullivan DJ, Phillips AO. Diabetes and renal disease: who does what? Clin Med 2013;13:460-4. https://doi.org/ 10.7861/clinmedicine.13-5-460

26. Camargo EG, Soares AA, Detanico AB, et al. The Chronic Kidney Disease Epidemiology Collaboration (CKD-EPI) equation is less accurate in individuals with type 2 diabetes when compared with healthy individuals. Diabet Med 2011;28:90-5. https://doi.org/10.1111/j.1464-5491. 2010.03161.x

27. Joint British Societies' consensus recommendations for the prevention of cardiovascular disease (JBS3). Heart 2014;10(Suppl 2):ii46-ii51. https://doi.org/10.1136/heartjnl-2014-305693

28. Abbott CA, Carrington AL, Ashe H, et al. The North-West Diabetes Foot Care Study: incidence of, and risk factors for, new diabetic foot ulceration in a community-based patient cohort. Diabet Med 2002;19:37784.

29. Steddon S, Sharples E. Renal Association clinical practice guideline in mineral and bone disorders in CKD. Nephron Clin Pract 2011;118(Suppl 1):c145-c152. https://doi.org/10.1159/000328066

30. Aspray TJ, Bowring C, Fraser W, et al. National Osteoporosis Society vitamin D guideline summary. Age Ageing 2014;43:592-5. https://doi.org/10.1093/ageing/afu093

31. Padhi S, Glen J, Pordes ABAJ, Thomas ME, on behalf of the Guideline Development Group. Management of anaemia in chronic kidney disease: summary of updated NICE guidance. BMJ 2015;350:32-6. https://doi.org/10.1136/bmj.h2258 